\begin{tabular}{|c|l|}
\hline Title & Near-infrared light control of membrane potential by an electron donor-acceptor linked molecule \\
\hline Author(s) & Takano, Yuta; Miyake, Kazuaki; Sobhanan, Jel adhara; Biju, Vasudevanpillai; T kachenko, Nikolai V.; Imahori, Hiroshi \\
\hline Citation & $\begin{array}{l}\text { Chemical communications, 56(83), 12562-12565 } \\
\text { https://doi.org/10.1039/d0cc05326k }\end{array}$ \\
\hline Issue Date & $2020-10-25$ \\
\hline Doc URL & http://hdl.handle.net/2115/83016 \\
\hline Type & article (author version) \\
\hline File Information & ChemCommun20200828C S-NIR.pdf \\
\hline
\end{tabular}

Instructions for use 


\section{Near-infrared light control of membrane potential by an electron donor-acceptor linked molecule $\dagger$}

Received 00th January 20xx, Accepted 00th January 20xx DOI: $10.1039 / \times 0 x x 00000 x$

www.rsc.org/

\author{
Yuta Takano, ${ }^{* a, b, c}$ Kazuaki Miyake, ${ }^{d}$ Jeladhara Sobhanan, ${ }^{c}$ Vasudevanpillai Biju, ${ }^{\text {a,c }}$ Nikolai V. \\ Tkachenko*e and Hiroshi Imahori*b,d
}

Near-infrared (NIR) light control of living cellular activities is a highly desired technique for living cell manipulation because of its advantage of the high penetrability towards living tissue. In this study, ( $\pi$-Extended porphyrin)-fullerene linked molecules are designed and synthesized to achieve NIR light control of the membrane potential. A donor-( $\pi$-extended porphyrin)-acceptor linked molecule exhibited the formation of the charge-separated state with a relatively long lifetime $(0.68 \mu \mathrm{s})$ and a moderate quantum yield (27-31\%). The hydrophilic trimethylammoniumlinked triad molecule successfully altered PC12 cells' membrane potential via the photoinduced intramolecular charge separation.

Since the near-infrared (NIR) light, especially with the wavelength in the optical window of biological tissues (generally, ca. $700-1500 \mathrm{~nm}$ ), ${ }^{1-3}$ is high tissue permeable and harmless, there has been a recent increase in demand for NIR light-mediated control of cellular functions. ${ }^{3-8}$ It can endow highly effective photoexcitation of target compounds in the living body with minimal accidental cell damage and sideeffects. ${ }^{9,10}$

Although semiconducting upconverting nanomaterials and metal nanoparticles have been reported using NIR light controls on biological events, ${ }^{3,6-8}$ the number of reports on organic molecules is still limited. ${ }^{1}$ One of the reasons is that NIR light absorption leads to form the lower-energy excited states of the molecules in comparison with UV or visible light absorption. The relatively small energy gap between the ground and excited

\footnotetext{
a. Research Institute for Electronic Science, Hokkaido University, Kita-20, Nishi-10, Sapporo 001-0020, Japan.E-mail: tak@es.hokudai.ac.jp

b. Institute for Integrated Cell-Material Sciences (WPI-iCeMS), Kyoto University,

Sakyo-ku, Kyoto 606-8501, Japan. E-mail: imahori@scl.kyoto-u.ac.jp

Graduate School of Environmental Science, Hokkaido University, Kita-10, Nishi-5,

Sapporo 060-810, Japan.

d. Department of Molecular Engineering, Graduate School of Engineering, Kyoto University, Nishikyo-ku, Kyoto 615-8510, Japan.

e. Faculty of Engineering and Natural Sciences, Tampere University,

Korkeakoulunkatu 8, Fl-33720 Tampere, Finland. E-mail:

nikolai.tkachenko@tuni.fi

† Footnotes relating to the title and/or authors should appear here.

Electronic Supplementary Information (ESI) available: [details of any supplementary information available should be included here]. See DOI: 10.1039/x0xx00000x
}

states shortens the lifetime of the excited state, inhibiting the use of light energy efficiently. Therefore, it is a challenge to establish the sophisticated molecular design guide for exploiting near-infrared light-triggered excited states.

As a target of light control on the cell, the cell membrane potential is attractive, as it governs a variety of essential cellular functions such as gene expression and signaling. ${ }^{11-13}$ However, the photocontrol of membrane potentials by NIR light in the optical window is still a major challenge due to the lack of general guidelines for proper molecular design based on the revelation of photophysical events. Against such background, to the best of our knowledge, no organic molecules were reported to control cell membrane potentials by NIR light.

In this study, novel donor-acceptor linked molecules featured by a $\pi$-extended porphyrin (Triad-NMe $\mathrm{N}_{3}$ : Fig. 1) were designed, synthesized, and characterized to attain efficient NIRlight control on the cell membrane potential. Although the photophysical properties of many donor-acceptor linked molecules have been intensively investigated so far, ${ }^{14-17}$ the effective use of a photoinduced charge-separated ( $p C S$ ) state generated by the NIR light is yet to be realized. Therefore, the present study demonstrates a systematical investigation on Triad-NMe $\mathrm{N}_{3}$ and its reference compounds (Figs. 1 and S1).

Recently, our research group developed a novel blue-light control method of cell membrane potential via pCS states in

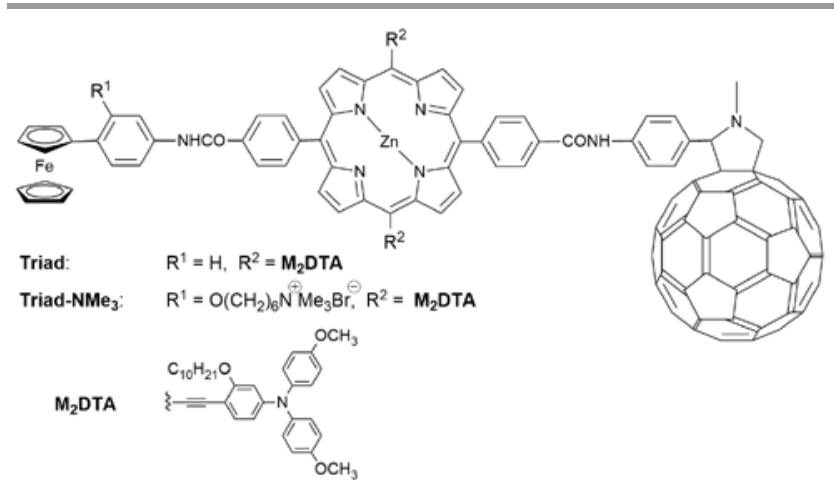

Fig. 1 Molecular structures of the porphyrin-fullerene linked molecules. 
Table 1. Optical properties of Q-bands and rate constants of photophysical processes ${ }^{a}$ in $\mathrm{PhCN}$

\begin{tabular}{|c|c|c|c|c|c|c|c|c|}
\hline compound & $\begin{array}{l}\text { Peak position of } \\
\text { the } Q \text { band }(\mathrm{nm})\end{array}$ & $\begin{array}{c}\varepsilon_{700 \mathrm{~nm}} \\
\left(\mathrm{M}^{-1} \mathrm{~cm}^{-1}\right)\end{array}$ & $\begin{array}{c}k_{0}^{\mathrm{s}} \\
\left(\mathrm{s}^{-1}\right)^{a, b}\end{array}$ & $\begin{array}{c}k_{1}^{\mathrm{s}} \\
\left(\mathrm{s}^{-1}\right)^{a, b}\end{array}$ & $\begin{array}{c}k_{0}^{\top} \\
\left(\mathrm{s}^{-1}\right)^{a, c}\end{array}$ & $\begin{array}{c}k_{\mathrm{CS} 1} \\
\left(\mathrm{~s}^{-1}\right)^{a}\end{array}$ & $\begin{array}{c}k_{\mathrm{CS} 2} \\
\left(\mathrm{~s}^{-1}\right)^{a}\end{array}$ & $\begin{array}{c}k_{\mathrm{CR}} \\
\left(\mathrm{s}^{-1}\right)^{a}\end{array}$ \\
\hline 15 & 706 & $1.07 \times 10^{5}$ & $7.7 \times 10^{8}$ & & $2.0 \times 10^{5}$ & & & \\
\hline ref- $C_{60}$ & & $4.00 \times 10^{2}$ & & & & & & \\
\hline Diad & 704 & $1.05 \times 10^{5}$ & & $1.8 \times 10^{9}$ & $3.1 \times 10^{6}$ & $9.8 \times 10^{8}$ & $2.9 \times 10^{6}$ & $2.4 \times 10^{6}$ \\
\hline Triad & 704 & $9.91 \times 10^{4}$ & & $1.6 \times 10^{9}$ & $3.6 \times 10^{6}$ & $8.4 \times 10^{8}$ & $3.4 \times 10^{6}$ & $1.5 \times 10^{6}$ \\
\hline
\end{tabular}

(a) See the experimental methods in ESI for the details to determine the rate constants which correspond to Scheme S1. (b) $k_{0} \mathrm{~s}, k_{1} \mathrm{~s}:$ Rate constant of the deactivation of the excited singlet state. i.e. $k_{0}=k_{\mathrm{Isc}}+k_{\mathrm{n}} \mathrm{s}, k_{1}=k_{\mathrm{Isc}}+k_{\mathrm{n}} \mathrm{s}+k_{\mathrm{cs} 1} . k_{\mathrm{Isc}}$ : Rate constant of intersystem crossing. $k_{\mathrm{n}} \mathrm{s}$ : Rate constant of internal conversion of the excited singlet state. (c) $k_{0}^{\top}$ : Rate constant of the deactivation of the triplet excited state.

donor-sensitizer-acceptor triads: ferrocene (Fc)-porphyrinfullerene $\left(\mathrm{C}_{60}\right)$ linked molecules. ${ }^{18,19}$ Photoinduced electron transfer occurs from the zincporphyrin excited singlet state $\left({ }^{1} \mathrm{Zn}^{*}\right)$ to the $\mathrm{C}_{60}$, followed by the $\mathrm{Fc}$ to the $\mathrm{ZnP}$ radical cation $\left(\mathrm{ZnP}^{\bullet+}\right)$, generating the $\mathrm{pCS}$ state, in which positive charge localizes on the $\mathrm{Fc}$ moiety $\left(\mathrm{Fc}^{+}\right)$and negative charge on the $\mathrm{C}_{60}$ moiety $\left(\mathrm{C}_{60^{-}}{ }^{-}\right)$, with high quantum yields (25-99\%) and sufficiently long lifetime (ca. $0.01 \mathrm{~ms}$ ). ${ }^{18}$ The transient huge electric field $\left(\sim 10^{6} \mathrm{~V} \mathrm{~cm}-1\right)$ was found to influence the membrane potential and ion channels in the living cells. ${ }^{16-19}$ Most of the molecules would be deactivated, and some would lead to electron transfer with the surrounding molecules. ${ }^{20}$ In our previous study, however, the use of potentially harmful blue light would hamper further developments of this light control method for practical applications. To overcome the obstacle, the light-harvesting property of the porphyrin moiety was modulated in the present work.

To achieve an efficient light-harvesting in the longer wavelength than pristine porphyrins, ${ }^{21}$ a $\pi$-extended porphyrin unit was applied by connecting the triarylamine derivative with a triple bond ( $\mathbf{M}_{\mathbf{2}} \mathbf{D T A}$, Fig. 1 ) to extend its $\pi$-electron system. ${ }^{22}$ 24 The introduction of the electron-donating groups can also
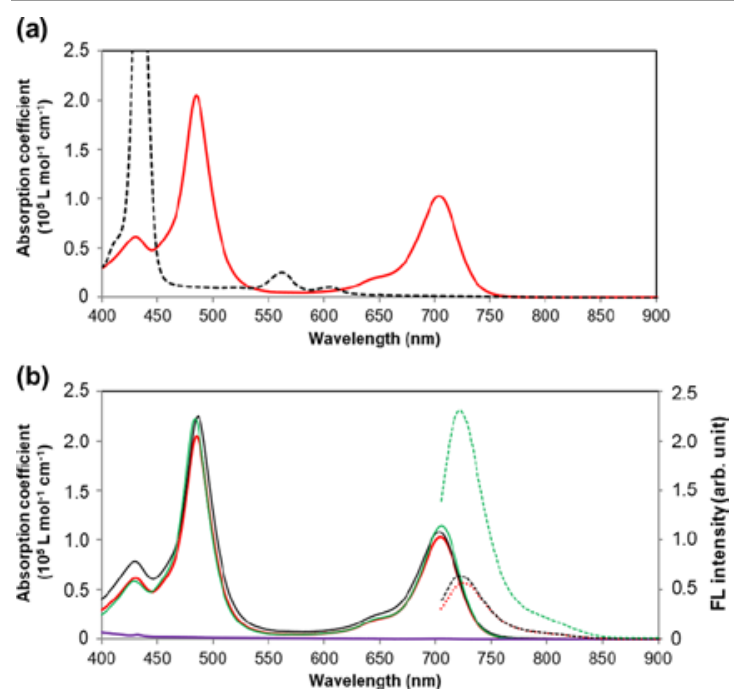

Fig 2. (a) UV-vis-NIR absorption spectra of Triad (solid red line) and ref-Triad (dashed black line) in PhCN. (b) UV-vis-NIR absorption spectra (solid line) and fluorescence (FL) spectra (dashed line) of Triad (red), Diad (black), 15 (green), and ref- $\mathrm{C}_{60}$ (purple) in PhCN. The FL spectra were recorded with $700 \mathrm{~nm}$ light excitation in which the absorbances of the molecules were adjusted to be identical (absorbance $=0.10$ at $700 \mathrm{~nm}$ ) enhance the electron-donating ability of the porphyrin. Accordingly, the decrease in both the energy levels of the excited singlet state and the charge-separated state would be counterbalanced not to decrease the driving forces for photoinduced electron transfer from the excited states. Two decyloxy chains in $\mathbf{M}_{\mathbf{2}}$ DTA moiety would suppress the undesired $\pi-\pi$ stacking that deactivates the photoinduced excited states of the porphyrin in a solution. ${ }^{13}$ The $\pi$-extended porphyrin was linked to an acceptor $\left(\mathrm{C}_{60}\right)$ to form Diad (Fig. S1). For Triad, an electron donor $(\mathrm{Fc})$ unit was further tethered to Diad to prolong the lifetime of the pCS state owing to the larger separation distance. A trimethylammonium moiety $\left(\mathrm{NMe}_{3}{ }^{+}\right)$was introduced into Triad (denoted as Triad-NMe $\mathbf{N}_{3}$ ) to offer water solubility and high affinity to the cell membrane. ${ }^{19}$ Characterization of the synthesized molecules was accomplished by spectroscopic methods including highresolution mass, IR, and NMR spectroscopies.

The optical, electrochemical, and photophysical properties of Triad, Diad, and the reference molecules were first investigated in PhCN. Since the absorption of the Fc moiety is much weaker than those of the $\mathrm{ZnP}$ and $\mathrm{C}_{60}$ moieties, the UVvis-NIR absorption spectra of Diad and Triad are virtually superpositions of those of the porphyrin moiety (15 in Fig S1) and the fullerene moiety (ref- $\mathbf{C}_{60}$ in Fig S1). This result implies that there is no significant electronic interaction between the porphyrin and $C_{60}$ moieties in their ground states. As shown in Fig. 2a, the characteristic absorption bands (i.e., the Soret band and Q-bands) of Triad in PhCN display bathochromic shifts relative to ref-Triad that does not possess the $\mathbf{M}_{2}$ DTA moiety (Figs. 2 and S1 Table 1). The Q-bands of Diad and Triad appear at $704 \mathrm{~nm}$, extending the absorption edge at $>750 \mathrm{~nm}$. The molar extinction coefficients $(\varepsilon)$ of 15 , Diad, and Triad are comparable: $1.07 \times 10^{5}, 1.05 \times 10^{5}$, and $9.91 \times 10^{4} \mathrm{M}^{-1} \mathrm{~cm}^{-1}$ at $700 \mathrm{~nm}$, which is the central wavelength of the light that will mostly be used in the present study. The $\varepsilon$ value of Triad at the peak position of the Q-band of the longest wavelength $(704 \mathrm{~nm}$, $1.02 \times 10^{5} \mathrm{M}^{-1} \mathrm{~cm}^{-1}$ ) is 10 times larger than that of ref-Triad (606 $\left.\mathrm{nm}, 1.03 \times 10^{4} \mathrm{M}^{-1} \mathrm{~cm}^{-1}\right)$. Thus, it is concluded that the introduction of the $\mathbf{M}_{\mathbf{2}}$ DTA moieties achieve sufficient lightharvesting ability in the optical window of the biological tissues.

The fluorescence spectra of Diad and Triad were quenched by ca. $70 \%$ relative to that of 15 (Fig. 2b). Because the absorption of the fullerene moiety is negligible at $725 \mathrm{~nm}$, which is the peak of the fluorescence of the porphyrin moiety, and the different distance dependence of electron and energy 
transfers, ${ }^{25}$ energy transfer from the ${ }^{1} \mathrm{ZnP} *$ to the fullerene moiety is not feasible. Consequently, the observed quenching by $70 \%$ indicates the intramolecular electron transfer from the ${ }^{1} \mathrm{ZnP} *$ to the fullerene moieties.

The redox potentials were measured to estimate the energy levels of the pCS states. In PhCN, the ZnP unit $\mathbf{1 5}$ showed the first and second oxidation potentials at +0.08 and $+0.25 \mathrm{~V}$ vs. $\mathrm{Fc} /$ Ferrocenium $\left(\mathrm{Fc}^{+}\right)$couple (Table S1). As predicted, the first oxidation potential was shifted to the negative direction by 0.26 $\mathrm{V}$ relative to that of the $\mathrm{ZnP}$ moiety $(+0.34 \mathrm{~V})$ in ref-Triad because of the presence of the electron-donating $\mathbf{M}_{\mathbf{2}}$ DTA moieties. ${ }^{14}$ For the $\mathrm{C}_{60}$ unit (ref- $\mathrm{C}_{60}$ ), the first reduction peak was observed at $-1.04 \mathrm{~V}$. The Fc unit (ref-Fc) revealed the first oxidation peak at $0.00 \mathrm{~V}$. The electrochemical data indicate that the energy levels of the pCS states relative to the ground state are $1.12 \mathrm{eV}$ for the $\mathrm{ZnP} / \mathrm{C}_{60}$ donor/acceptor pair and $1.04 \mathrm{eV}$ for the $\mathrm{Fc} / \mathrm{C}_{60}$ pair in $\mathrm{PhCN} .{ }^{23}$ Because these levels are significantly lower than the excited singlet state $\left(\mathrm{S}_{1}=1.74 \mathrm{eV}\right)$ and triplet excited state $\left(T_{1}=1.24 \mathrm{eV}\right.$, Fig. S6) of the $\mathrm{ZnP}$ of $\mathbf{1 5}$ as well as that of Diad and Triad, the formation of the pCS states is energetically feasible in Diad and Triad (Scheme S1). In fact, the driving forces for electron transfer from the ${ }^{1} \mathrm{ZnP} *$ and the excited triplet state $\left({ }^{3} \mathrm{ZnP} *\right)$ to the $\mathrm{C}_{60}$ moiety are $0.62 \mathrm{eV}$ and $0.12 \mathrm{eV}$, which are comparable to those in ref-Triad $(0.66 \mathrm{eV}$ and $0.15 \mathrm{eV}),{ }^{14}$ ensuring the smooth electron transfer.

Femto-pico-second (fs-ps) and nanosecond (ns) timeresolved transient absorption (TA) measurements were performed by exciting the sample at $700 \mathrm{~nm}$ to elucidate the photoinduced processes of the compounds. The overall photophysical processes are depicted in Scheme S1. Kinetic rate constants for the formation of the pCS states $\left(k_{\mathrm{CS}}\right)$ and their charge recombination $\left(k_{\mathrm{CR}}\right)$ are summarized in Table 1 , and the detailed discussion on the analyses is provided in the ESI (Figs. S6-S10). The $k_{\mathrm{CR}}$ value of Triad $\left(1.5 \times 10^{6} \mathrm{~s}^{-1}\right)$ is smaller by ca. $40 \%$ than that of Diad $\left(2.4 \times 10^{6} \mathrm{~s}^{-1}\right)$. This result exemplifies an effective suppression of the $C R$ to the ground state by the second intramolecular electron transfer by the Fc moiety, generating the more distantly separated $\mathrm{Fc}^{+} / \mathrm{C}_{60}{ }^{\circ-}$ pair than the $\mathrm{ZnP}{ }^{*+} / \mathrm{C}_{60^{\circ-}}$ pair. The quantum yield of the final pCS state ( $\left.\Phi_{\mathrm{CS}}\right)$ can be determined by comparing intensities of the peaks arising from the fullerene anion $\left(\mathrm{C}_{60^{-}}{ }^{-}\right)$between Triad and ref-Triad $\left(\Phi_{\mathrm{CS}}=99 \%\right) .{ }^{17}$ The yield of pCS of Triad is estimated to be $31 \%$. Alternatively, the $\Phi_{\mathrm{cS}}$ value can be calculated from the obtained kinetic rate constants (see the ESI for the detail) based on Scheme 51 . The $\Phi_{\mathrm{CS}}$ values are 33\% for Diad and $27 \%$ for Triad. The calculated $\Phi_{\mathrm{CS}}$ value of Triad ( $27 \%$ ) agrees well with the value determined by the comparative method (31\%), supporting the validity of the kinetic analysis. Consequently, the lifetime and $\Phi_{\mathrm{CS}}$ value of the pCS state of Triad (0.68 $\left.\mu \mathrm{s}, 27-31 \%\right)$ are likely sufficient to conduct the NIR light control of membrane potential via the pCS state.

On the basis of the photophysical properties of Triad, we envisioned that cell membrane potentials could be changed by the effect via the long-lived pCS states, which are equivalent to the large electric field at the nanometer scale. ${ }^{16,18,19}$ A watersoluble form of Triad, that is Triad-NMe $\mathrm{N}_{3}$, was used for the cell experiments. In DMSO, Triad- $\mathrm{NMe}_{3}$ also showed characteristic fluorescence from the ZnP moiety around $740 \mathrm{~nm}$ (Fig. S11), as in the case in $\mathrm{PhCN}$. The fluorescence spectrum was quenched by ca. $50 \%$ compared to that of a water-soluble porphyrin reference 16, suggesting the occurrence of the photoinduced electron transfer. In the ns-TA measurements, Triad- $\mathrm{NMe}_{3}$ evidenced the formation of pCS after the excitation at $700 \mathrm{~nm}$ (Fig. S7c, Table S1). The signal and decay arising from $\mathrm{C}_{60} 0^{\circ}$ - were clearly observed similar to Triad in PhCN, and fitted by the biexponential fitting. Two components were ascertained with $k_{\mathrm{CR}}$ $=1.0 \times 10^{6} \mathrm{~s}^{-1}(48 \%)$ and $1.1 \times 10^{5} \mathrm{~s}^{-1}(52 \%)$ in deaerated DMSO. The fast component can be attributed to the monomeric state, and the slow component is rationalized by the stabilization of $\mathrm{C}_{60}{ }^{\circ-}$ assisted by the possible aggregates. ${ }^{18,19}$

For an application of molecules for light control on cells, the production of ${ }^{1} \mathrm{O}_{2}$ should be suppressed to avoid undesired sideeffects by its cytotoxicity. ${ }^{15}$ The production of ${ }^{1} \mathrm{O}_{2}$ under $700 \mathrm{~nm}$ light illumination was examined by using a ${ }^{1} \mathrm{O}_{2}$ selective fluorogenic reagent Singlet Oxygen Sensor Green (SOSG) ${ }^{26}$ (Fig. $\mathrm{S} 12$ ). It was confirmed that the ${ }^{1} \mathrm{O}_{2}$ production ability of Triad$\mathrm{NMe}_{3}$ is negligible, in sharp contrast to that of $\mathbf{1 6}$ (Fig. S1). Efficient quenching of the ${ }^{1} \mathrm{ZnP} *$ and ${ }^{3} \mathrm{ZnP} *$ states by the $\mathrm{C}_{60}$ moiety via photoinduced electron transfer in Triad- $\mathrm{NMe}_{3}$ competes well with undesirable quenching by $\mathrm{O}_{2}$ in the highly polar environment (1\% DMSO in water), suppressing the production of ${ }^{1} \mathrm{O}_{2}$. Therefore, the introduction of fullerene moiety to the $\pi$-extended porphyrin is an effective way to reduce the phototoxicity caused by ${ }^{1} \mathrm{O}_{2}$.

Triad-NMe $\mathrm{N}_{3}$ was then delivered to PC12 cells by applying the DMSO $/ \mathrm{H}_{2} \mathrm{O}$ solution of Triad-NMe $\mathrm{N}_{3}$. Incorporation of Triad$\mathrm{NMe}_{3}$ into the surface membrane was visualized by a confocal laser scanning microscopy (Fig. S13), and the incorporated number of molecules was estimated at $1.3 \times 10^{7}$ molecules/cell. The inhomogeneous distribution implies the aggregate formation of Triad-NMe $\mathbf{N}_{3}$ in the cell membrane as in the case for ref-Triad-NMe ${ }_{3}{ }^{18}$ Therefore, it is concluded that the observed

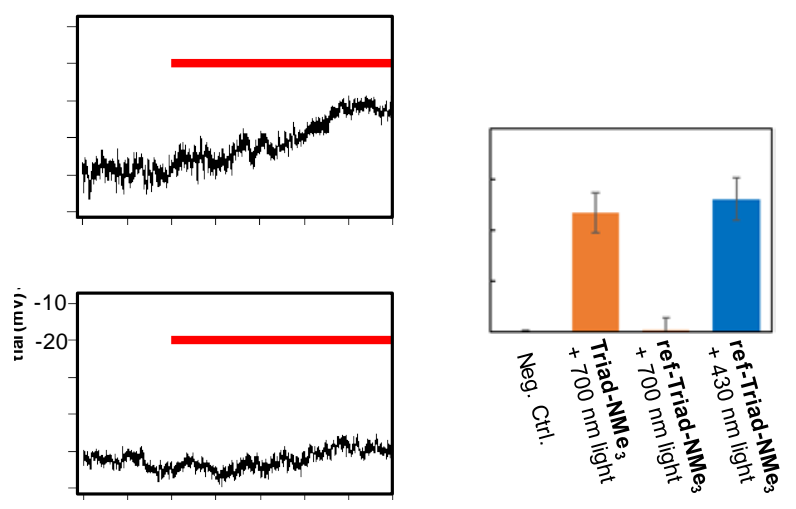

Fig. 3 Representative traces of photoinduced depolarization in a PC12 cell incorporated (a) with and (b) without Triad-NMe $\mathbf{N}_{3}$ recorded by a planer patch-clamp method $(n=6)$. Xe-lamp with a $700 \pm 6 \mathrm{~nm}$ band-pass filter, Power: $20 \mathrm{~mW} \mathrm{~cm}^{-2}$, r.t. $\quad$ (c) Degrees of the change in membrane potential of PC12 cells after $5 \mathrm{~min}$ of the illumination $\left(100 \mathrm{~mJ} \mathrm{~cm}^{-2}\right)$. Xe-lamp with a $700 \pm 6 \mathrm{~nm}$ or a $430 \pm 5 \mathrm{~nm}$ band-pass filter. Error bars indicate S.D. Statistically significant differences between the negative control and each compound are indicated with asterisks $(* * * \mathrm{P}<0.001)$. 
distribution of Triad-NMe $\mathrm{N}_{3}$ is sufficient to examine the effect of Triad- $\mathrm{NMe}_{3}$ on the photoinduced change in the membrane potential of PC12 cells.

The ability of Triad-NMe $\mathrm{NM}_{3}$ to induce depolarization was investigated by a planer patch-clamp method (Fig. 3). Multiple experiments corroborated that $\mathrm{Triad}-\mathrm{NMe}_{3}$ can successfully alter the membrane potential of PC12 cells by light illumination at $700 \mathrm{~nm}$. Meanwhile, ref-Triad-NMe $\mathrm{N}_{3}$, which can induce depolarization under blue light illumination but does not absorb $700 \mathrm{~nm}$ light, did not cause the photoinduced depolarization by the NIR light. The average depolarization induced by Triad$\mathrm{NMe}_{3}$ was $+12 \mathrm{~V}$ after $5 \mathrm{~min}$ irradiation at $700 \mathrm{~nm}$, comparable to that obtained by ref-Triad-NMe $\mathrm{N}_{3}$ under blue light illumination (Fig. 3c). This level of change is expectedly large enough to trigger various cellular events such as neural firing. ${ }^{17}$ MTT-assay confirmed that the current experimental conditions (i.e. the concentration of Triad-NMe $\mathrm{N}_{3}$ and intensity of the NIR light) did not cause any significant cytotoxicity on PC12 cells (Fig. S14). Accordingly, Triad-NMe $\mathrm{N}_{3}$ was found to be a promising molecule to manipulate the membrane potential under NIR light illumination.

In summary, a new donor- $\pi$-extended sensitizer-acceptor linked molecule Triad-NMe $\mathbf{N}_{3}$ was designed and synthesized to demonstrate the proof of the concept for utilizing NIR light to control cell membrane potential via a pCS state. The introduction of the electron-donating $\mathbf{M}_{\mathbf{2}} \mathrm{DTA}$ moieties to the porphyrin core through triple bonds strikingly enhanced the absorption properties in the NIR region in terms of wavelength and molar extinction coefficient. The photophysical studies on Triad-NMe $\mathrm{N}_{3}$ revealed the formation of the pCS state with a relatively long lifetime $(\tau=0.68 \mu \mathrm{s})$ and a moderate quantum yield (27-31\%). Triad- $\mathrm{NMe}_{3}$ enables us to modulate the membrane potential using cell penetrative and non-cytotoxic NIR light within the biologically beneficial optical window. The notable guidelines for the molecular design are the structure to obtain effective pCS quantum yield by introducing bulkier electron-donating substituents into the porphyrin core to avoid the undesirable rapid internal conversion of the excited singlet state to the ground state. The present study paves a way to develop photochemical molecular probes for precise spatiotemporal control on membrane potential and its related cellular activities ${ }^{11-13,27}$ by NIR light.

\section{Conflicts of interest}

There are no conflicts to declare.

\section{Acknowledgements}

This work is supported by Grants-in-Aid for Scientific Research (S) (25220801), (C) (15K05563), MEXT, Japan. The iCeMS is supported by World Premier International Research Center Initiative (WPI), MEXT, Japan. We acknowledge the CeMI for the microscopic measurements and the Dynamic Alliance for Open Innovation Bridging Human, Environment and Materials, and JSPS Core-to-Core Program, for their support.

\section{Notes and references}

1 C. Brieke, F. Rohrbach, A. Gottschalk, G. Mayer and A. Heckel, Angew. Chem. Int. Ed., 2012, 51, 8446-8476.

2 A. M. Packer, B. Roska and M. Hausser, Nat. Neurosci., 2013, 16, 805-815.

3 J. Li and K. Pu, Acc. Chem. Res., 2020, 53, 752-762.

4 J. O. Escobedo, O. Rusin, S. Lim and R. M. Strongin, Curr. Opin. Chem. Biol., 2010, 14, 64-70.

5 S. Hososhima, H. Yuasa, T. Ishizuka, M. R. Hoque, T. Yamashita, A. Yamanaka, E. Sugano, H. Tomita and H. Yawo, Sci. Rep., 2015, 5, 16533:1-10.

6 M. F. Tsai, S. H. G. Chang, F. Y. Cheng, V. Shanmugam, Y. S. Cheng, C. H. Su and C. S. Yeh, ACS Nano, 2013, 7, 5330-5342.

7 J. Song, J. Bin Pan, W. Zhao, H. Y. Chen and J. J. Xu, Chem. Commun., 2020, 56, 6118-6121.

8 J. Liu, L. Pan, C. Shang, B. Lu, R. Wu, Y. Feng, W. Chen, R. Zhang, J. Bu, Z. Xiong, W. Bu, J. Du and J. Shi, Sci. Adv., 2020, 6, 1-11.

9 J. P. Celli, B. Q. Spring, I. Rizvi, C. L. Evans, K. S. Samkoe, S. Verma, B. W. Pogue and T. Hasan, Chem. Rev., 2010, 110, 2795-2838.

10 L. Zou, H. Wang, B. He, L. Zeng, T. Tan, H. Cao, X. He, Z. Zhang, S. Guo and Y. Li, Theranostics, 2016, 6, 762-772.

11 S. Sundelacruz, M. Levin and D. L. Kaplan, Stem Cell Rev. Reports, 2009, 5, 231-246.

12 R. D. Fields, F. Eshete, B. Stevens and K. Itoh, J. Neurosci., 1997 17, 7252-7266.

13 S. S. McDaniel, O. Platoshyn, Y. Yu, M. Sweeney, V. A. Miriel, V. A. Golovina, S. Krick, B. R. Lapp, J.-Y. Wang and J. X.-J. Yuan, J. Appl. Physiol., 2001, 91, 2322-2333.

14 H. Imahori, K. Tamaki, D. M. Guldi, C. P. Luo, M. Fujitsuka, O. Ito, Y. Sakata and S. Fukuzumi, J. Am. Chem. Soc., 2001, 123, 2607-2617.

15 C. Schweitzer and R. Schmidt, Chem. Rev., 2003, 103, 16851757.

16 D. Gosztola, H. Yamada and M. R. Wasielewski, J. Am. Chem. Soc., 1995, 117, 2041-2048.

17 D. Sasikumar, Y. Takano and V. Biju, Chem. - A Eur. J., 2020, 26, 2060-2066.

18 Y. Takano, T. Numata, K. Fujishima, K. Miyake, K. Nakao, W. D. Grove, R. Inoue, M. Kengaku, S. Sakaki, Y. Mori, T. Murakami and H. Imahori, Chem. Sci., 2016, 7, 3331-3337.

19 N. Cai, Y. Takano, T. Numata, R. Inoue, Y. Mori, T. Murakami and H. Imahori, J. Phys. Chem. C, 2017, 121, 17457-17465.

20 Y. Takano, R. Munechika, V. Biju, H. Harashima, H. Imahori and Y. Yamada, Nanoscale, 2017, 9, 18690-18698.

21 K. M. Kadish, K. M. Smith and R. Guilard, Handbook of Porphyrin Science (Volumes 1), 2010. World Scientifics, Singapore.

22 K. M. Kadish, K. M. Smith and R. Guilard, Handbook of Porphyrin Science (Volumes 2), 2010. World Scientifics, Singapore.

23 D. Koszelewski, A. Nowak-Król, M. Drobizhev, C. J. Wilson, J. E. Haley, T. M. Cooper, J. Romiszewski, E. Górecka, H. L. Anderson, A. Rebane and D. T. Gryko, J. Mater. Chem. C, 2013, 1, 2044-2053.

24 Satrialdi, R. Munechika, V. Biju, Y. Takano, H. Harashima and Y. Yamada, Chem. Commun., 2020, 56, 1145-1148.

25 T. Higashino, T. Yamada, M. Yamamoto, A. Furube, N. V. Tkachenko, T. Miura, Y. Kobori, R. Jono, K. Yamashita and H. Imahori, Angew. Chem. Int. Ed., 2016, 55, 629-633.

26 H. Matsui, O. Shimokawa, T. Kaneko, Y. Nagano, K. Rai and I. Hyodo, J. Clin. Biochem. Nutr, 2011, 48, 107-111.

27 S. K. Bagal, A. D. Brown, P. J. Cox, K. Omoto, R. M. Owen, D. C. Pryde, B. Sidders, S. E. Skerratt, E. B. Stevens, R. I. Storer and N. A. Swain, J. Med. Chem., 2013, 56, 593-624. 